\title{
Obligaciones éticas y deberes fiduciarios del representante legal de los miembros del comité de supervisión de una cooperativa
}

Ethical obligations and fiduciary duties of legal representative from members of the supervising committee of a cooperative

Obrigações éticas e deveres fiduciários do representante legal da os membros do conselho fiscal de uma cooperativa

\section{Juan Enrique Santana Félix ${ }^{1}$}

Recibido: 10 de noviembre de 2019

Aprobado: 15 agosto de 2020

Publicado: 30 de septiembre de 2020

Cómo citar este artículo:

Santana Félix, J.E. (2020). Obligaciones éticas y deberes financieros del representante legal de los miembros del comité de supervisión de una cooperativa.

Cooperativismo \& Desarrollo, 28(118), 1-22.

doi: https://doi.org/10.16925/2382-4220.2020.03.04

Artículo de investigación. https://doi.org/10.16925/2382-4220.2020.03.04

1 Abogado egresado de la Pontificia Universidad Católica de Puerto Rico, Escuela de Derecho. Instructor en el Instituto de Cooperativismo de la Universidad de Puerto Rico y del Centro Nacional de Servicios Educativos (CENASE); miembro del Comité de Relaciones con el Estado de la Liga de Cooperativas de Puerto Rico.

Correo electrónico: abogadosantana@yahoo.com

ORCID: http://orcid.org/0000-0003-0410-9436 
2 Obligaciones éticas y deberes fiduciarios del representante legal de los miembros del comité de supervisión de una cooperativa

\section{Resumen}

El análisis que se realiza en este artículo intenta traer a la discusión pública las funciones, responsabilidades y deberes que se le asigna a los comités de supervisión o juntas de vigilancias (como comúnmente se les conoce en Latinoamérica), su alegada independencia y autonomía y sobre todo las obligaciones de naturaleza ética profesional que aplican al profesional del derecho contratado por este tipo de comités, cuando, en el ejercicio del cumplimiento de su responsabilidad fiduciaria, deciden seleccionarlo para descargar esta responsabilidad. En consecuencia, se analizan las leyes vigentes que regulan a las cooperativas en Puerto Rico, se menciona la intervención del organismo de gobierno que fiscaliza estos comités y la posición adoptada por estos organismos de gobierno sobre el tema de los comités de supervisión, los cánones de ética aplicables a la profesión legal y se mencionan precedentes judiciales relacionados con asuntos de naturaleza ética.

Palabras clave: órganos de administración y control democrático, cánones de ética profesional, responsabilidad fiduciaria, gobierno cooperativo, acto cooperativo.

\section{Resumo}

A análise realizada neste artigo procura trazer à discussão pública as funções, responsabilidades e deveres atribuídos aos comitês de fiscalização ou órgãos de vigilância (como são comumente conhecidos na América Latina), sua alegada independência e autonomia e sobre todas as obrigações de natureza ética profissional que se aplica ao profissional jurídico contratado por este tipo de comitês, quando, no exercício de sua responsabilidade fiduciária, decidam selecioná-lo para cumprir essa responsabilidade.

Consequentemente, são analisadas as atuais leis que regulam as cooperativas em Porto Rico, mencionando-se a intervenção do órgão governamental que tutela esses comitês e a posição adotada por esses órgãos governamentais sobre o tema dos comitês de supervisão, os cânones de ética aplicáveis ao são mencionadas profissões jurídicas e precedentes judiciais relacionados a questões de natureza ética.

Palavras-chave: organismos democráticos de gestão e controle, diretrizes éticas profissionais, responsabilidade fiduciária, governo cooperativo, ato cooperativo.

\section{Abstract}

The analysis carried out in this article attempts to bring to the public discussion the functions, responsibilities and duties assigned to the supervisory committees or vigilance boards (as they are commonly known in Latin America), their alleged independence and autonomy and on all the obligations of a professional ethical nature that apply to the legal professional hired by this type of committees, when, in the exercise of their fiduciary responsibility, they decide to select him to discharge this responsibility.

Consequently, the current laws that regulate cooperatives in Puerto Rico are analyzed, mention is made of the intervention of the government body that oversees these committees and the position adopted by these government bodies on the subject of supervision committees, the canons of ethics applicable to the legal profession and judicial precedents related to matters of an ethical nature are mentioned.

Keywords: democratic administrative and control organisms, professional ethical guidelines, fiduciary responsibility, cooperative government, cooperative act 


\section{Introducción}

En la gran mayoría de las cooperativas de ahorro y crédito del Caribe, Centro y Suramérica, sin excluir países de otras latitudes, existen, por mandato legislativo, los llamados comités de supervisión o juntas de vigilancia. Para poder desempeñar en forma efectiva sus funciones, deberes y responsabilidades estos organismos requieren de la asistencia profesional externa; lo que conlleva, en el caso de los representantes legales, un deber de lealtad que involucra confidencialidad y privilegios que expondremos en el presente artículo. Esta investigación se dirige a los miembros de estos comités o a quienes mantienen una relación profesional de asesoramiento legal con estos cuerpos directivos.

Generalmente, las comunicaciones iniciales entre los miembros de un comité de supervisión y sus representantes legales comienzan con una comunicación ex parte o solicitud de propuesta de servicios legales para que les asesore y represente en el descargo de sus responsabilidades ministeriales, según lo requieren las distintas leyes que, en el caso de Puerto Rico, surgen del Artículo 5.13 de la Ley Núm. 255 del 28 de octubre de 2002, según enmendada, conocida como "Ley general de sociedades cooperativas de ahorro y crédito de Puerto Rico". Esta legislación le concede a los miembros del comité de supervisión total autonomía para el cabal descargo de sus responsabilidades fiduciarias y ministeriales.

La propuesta de ley general es sometida al escrutinio y análisis de los miembros del comité de supervisión que, en el ejercicio de sus facultades autónomas, pasan juicio, evalúan y determinan si recomiendan la contratación del profesional (seleccionado por ellos) para que funja como su asesor y representante legal ante las autoridades pertinentes, incluyendo los distintos componentes de la cooperativa. Este ejercicio se tiene que realizar descargando su autonomía e independencia y dentro de los parámetros, lineamientos, normas y especificaciones de la Política de Contratación de Servicios Profesionales que hayan adoptado los miembros de la junta de directores o el consejo de administración. Después de que los integrantes del comité de supervisión efectúan la selección del profesional del derecho, se instruye al principal ejecutivo de la Cooperativa para que formalice la contratación, en representación de los miembros del comité, teniendo en cuenta también la forma como está estructurada la cooperativa y su naturaleza jurídica, única en su clase (sui generis) que no se puede confundir o asemejar a una corporación regular cuya estructura organizacional es distinta. Es importante señalar que, a las cooperativas, por disposición de ley, se les obliga a crear un comité de supervisión, distinto a lo que sucede en las corporaciones regulares en las que esa forma de gobernanza y filosofía no existe. 
En nuestro caso, las leyes vigentes aplicables a las cooperativas imponen a estos cuerpos directivos unas responsabilidades fiduciarias, legales y ministeriales que no son delegables y sobre las cuales no puede intervenir la junta de directores, el consejo de administración, el principal ejecutivo o cualquiera otro asesor legal de la cooperativa. Precisamente porque las personas que integran los comités de supervisión son socios de la cooperativa que, una vez electos o designados, responden exclusivamente a la asamblea de la cooperativa representada por los socios dueños, quienes en un ejercicio de democracia participativa anualmente eligen directamente a sus miembros y por tanto su lealtad es con estos y no con otros empleados, gerenciales, personas o profesionales contratados por la entidad.

Según la doctrina y las leyes vigentes en Puerto Rico, la asamblea de socios o delegados es la autoridad máxima de la entidad y sus decisiones son obligatorias para todos los componentes de la cooperativa. Esta última, además, elige a las personas que le van a representar en los dos únicos cuerpos directivos de elección, esto es, la junta de directores o consejo de administración y el comité de supervisión; en términos de jerarquía, ambos cuerpos directivos están al mismo nivel, ubicándose al principal ejecutivo en un nivel inferior en la escala jerárquica institucional.

Con respecto al descargo de las responsabilidades que las leyes vigentes imponen a estos comités, se encuentra el deber de vigilar la legalidad de los actos de la Junta y la Gerencia, el de fiscalizar a los componentes de la cooperativa, entre otros. Esto demanda pericia y justifica el hecho de que, en múltiples ocasiones, se tenga que contratar los servicios de un asesor legal o perito en materia jurídica, incluyendo la participación y representación activa de este en las asambleas anuales y ante otras autoridades competentes

Según el Artículo 5.13 (a) y (f) de nuestra Ley 255-2002, supra, los miembros del Consejo Superior de Sociedades Cooperativas de Ahorro y Crédito (CSA) están facultados para realizar las intervenciones que consideren necesarias o convenientes para alcanzar los mejores intereses de la cooperativa, actuando como lo haría "el buen padre de familia"1; así mismo, el Artículo 10 de la Ley 255-2002, según enmendada, señala, como parte de las responsabilidades de los miembros del CSA, el deber de vigilar la legalidad de los actos de la junta y la gerencia.

Para que esa contratación se gestione libre de ataques infundados sobre un aparente conflicto de intereses, el proponente de los servicios legales para los

1 Es una expresión muy antigua que proviene del Derecho Romano y que se utiliza para medir o determinar si una persona ha actuado de manera negligente en el descargo de sus responsabilidades o en el cuidado de algo que se le ha delegado. Por tanto, si la ley o alguna forma de obligación le impone un deber y no lo cumplió, o lo cumplió mal, se le debe imponer responsabilidad legal y posiblemente económica. 
miembros del comité de supervisión debe evitar reunirse con integrantes de la junta de directores, el consejo de administración o con el principal ejecutivo de la cooperativa (por ejemplo, con el fin de discutir los términos y condiciones de su contrato o cualquier otro propósito). Por el contrario, toda su intervención en la cooperativa, incluyendo la participación en las asambleas que puedan celebrarse, debe circunscribirse al asesoramiento y representación única y exclusiva de sus clientes (los miembros del CSA), de modo que no exista la posibilidad de ataques o de impedimentos por ningún canon de ética, si hay alguno aplicable. De esta forma podrá asesorar y brindar su representación legal en el descargo de sus funciones, deberes y obligaciones ministeriales, de conformidad con los requerimientos de las leyes vigentes en su jurisdicción.

Habrá conflicto de intereses cuando el representante legal, al ser contratado por la cooperativa, se convierta en el abogado de la organización y no de los miembros del comité de supervisión. En ese caso, los miembros de estos comités no podrán contar con una representación legal adecuada para descargar sus responsabilidades ministeriales porque sus intereses se cruzarán con los demás componentes de la institución (aquellos que por obligación debe supervisar y fiscalizar), incluso con la propia cooperativa. Pretender lo contrario, es tanto como promover que los miembros del comité de supervisión, en el descargo de sus responsabilidades ministeriales, estén impedidos para acudir ante las autoridades competentes, incluyendo el organismo que los supervisa y regula o ante el Foro Judicial, pues no contarían con representación legal adecuada para exigir el cumplimiento de las reglas, normas, reglamentos y leyes aplicables a las cooperativas. Tampoco podrían realizar aquellas intervenciones que consideren necesarias para velar por los intereses de la cooperativa, y mucho menos contratar un profesional que les ayude a descargar sus responsabilidades ministeriales.

Uno de los valores de mayor importancia que promueve el Movimiento Cooperativo es la transparencia en la toma de decisiones de todos los niveles de gobernanza en una cooperativa. Para esto, las propias leyes crean un cuerpo directivo, electo por la asamblea que es de naturaleza "Soberana" y forma parte de la gobernanza cooperativa, para impedir la delegación a terceros extraños de sus deberes. Por el contrario, para que los CSA pudieran cumplir con la responsabilidad fiduciaria que le imponen las leyes, la Corporación para la Supervisión y Seguro de Cooperativas en Puerto Rico (COSSEC), responsable de fiscalizar y supervisar a todas las cooperativas nacionales, emitió en 2001 la Carta Circular 01-03, desde entonces vigente, expresando y exhortando a las cooperativas a asignarles las herramientas necesarias para el mejor descargo de sus funciones, ya que no hacerlo implicaría una crasa violación a la ley. Estas herramientas incluyen el asesoramiento externo, es decir, la contratación de 
6 Obligaciones éticas y deberes fiduciarios del representante legal de los miembros del comité de supervisión de una cooperativa

profesionales, sencillamente porque la ley no exige (ni requiere) a los que interesados en formar parte de estos cuerpos directivos, de una preparación académica que deban o tengan que cumplir en el ejercicio democrático que les reconoce la ley. Quienes deseen aspirar o ser electos en un comité de supervisión deben cumplir múltiples funciones, relacionadas con:

a) Detalles de las finanzas

b) La condición económica de la cooperativa

c) Asuntos de naturaleza legal

d) Contabilidad

e) Querellas

f) Demandas judiciales

g) Reclamos del organismo regulador

h) Investigaciones sobre asuntos relacionados con socios

i) Hallazgos de auditorías realizadas por auditores internos, externos y por el propio organismo regulador

j) Revisar y validar los estados financieros, emitidos con base en las normas de contabilidad vigentes

k) Fiscalizar para que no se violenten las políticas, reglas y normas adoptadas por los miembros de la junta de directores, el consejo de administración o la asamblea, lo que demanda asesoramiento legal, tal y como ocurrió en el caso que provoca la queja

I) Supervisar el funcionamiento interno, financiero, contable y administrativo

m) Revisar los planes de trabajo de todos los cuerpos directivos, incluyendo la junta de directores o el consejo de administración, y también de otros comités (por ejemplo la administración), para garantizar que estos se ejecuten en los términos autorizados por la asamblea

n) Llevar a cabo inspección de los ingresos y gastos

o) Realizar una valoración global de los ingresos y gastos, a través de la comparación con el año anterior, la planificación, el pronóstico y los datos externos

p) Inspecciones de muestras aleatorias de gastos individuales de mayor magnitud

q) Revisión periódica de muestras aleatorias de los gastos correspondientes a la junta de directores o consejo de administración

r) Valoración de la política de requisitos de la junta de directores o el consejo de administración 
s) Inspección de la cartera de crédito

t) Revisión de los límites máximos a prestar a un asociado, según lo estipulado

u) La clasificación de cartera y la suficiencia de estimaciones; cumplimiento del Manual de políticas crediticias

v) Calidad de las garantías; capacidad de pago y comportamiento de pago del deudor

w) Seguimiento de crédito

x) Evolución de la cartera de crédito

y) Existencia de avalúos, entre otros,

Estas funciones demuestran la seriedad de la gestión de fiscalización y vigilancia, que recaen exclusivamente en los miembros del comité de supervisión. También requieren de mucha dedicación, seriedad, conocimientos técnicos especializados, asesoramiento legal, contable y compromisos; además, para ser atendidas y descargadas, requieren de la pericia, el conocimiento y la capacidad técnica. No cumplir con las exigencias de la ley implicaría una violación a la responsabilidad fiduciaria que, según el Artículo 10.01 de la Ley 255, supra, incluye lo siguiente:

Artículo 10.01 - Deberes (a) Los miembros de los cuerpos directivos de una cooperativa están sujetos a un deber de fiducia para con la cooperativa. Este deber de fiducia incluye el deber de diligencia y el deber de lealtad para con la cooperativa, así como el deber de velar y de cuidar como un buen padre de familia de los bienes y operaciones de la cooperativa, así como de los haberes, acciones y depósitos de socios y depositantes que obran en la institución.

(b) Los miembros de los cuerpos directivos, delegados y empleados de una cooperativa no podrán incurrir en conflictos de intereses directos ni indirectos con relación a la cooperativa. Todo miembro de los cuerpos directivos, delegado y empleado de la cooperativa estará sujeto a las siguientes prohibiciones éticas de carácter general [...].

De acuerdo con Muñoz, "un buen gobierno corporativo implica unidad entre poder y responsabilidad en la alta dirección de una empresa, ya que, de no existir este factor, los altos ejecutivos pueden 'cocinar los registros contables' de la institución a su conveniencia y hacer ver excelente su situación, evadiendo responsabilidad más tarde cuando los hechos son descubiertos" (Revista COLAC, 2006). En la "XVI conferencia regional. Responsabilidad social cooperativa y vida democrática", la investigadora 
Mayrand Ríos Barboza (2008) invitaba a pensar en ¿cuáles políticas e instrumentos legales debían existir inherentes al buen funcionamiento de los comités de vigilancia? y ¿cuáles eran las mejores herramientas para que los comités de vigilancia tuvieran la facilidad de dar seguimiento a la transparencia en las cooperativas?²

En la "XV Conferencia Regional de ACl-Américas", donde se presentó una versión preliminar del documento de la Ley Marco para las Cooperativas de América, se destaca que los CSA tienen la función de vigilar a la cooperativa, mediante una junta de vigilancia (comité de supervisión), sin perjuicio de la tarea que corresponde a la auditoría y la supervisión. También es su deber fiscalizar la actividad de la cooperativa y velar porque la junta de directores o consejo de administración cumpla con la ley, el estatuto aplicable, los reglamentos y las resoluciones asamblearias. Esa función de vigilancia recae en un órgano colegiado compuesto por socios que deben asegurar el cumplimiento de la ley, de los estatutos y de los reglamentos aplicables; este órgano colegiado también debe delimitar sus funciones, cuidando de no entorpecer las de otros organismos de la cooperativa y advirtiendo que su adecuado desempeño es fundamental para la buena marcha de la entidad. Sobre este tema, Álvaro Duran Vargas (2004) señala que "el verdadero papel de la Junta de Vigilancia, en la práctica, no es el que las leyes le exigen, sino más bien, es el de valerse de terceros especializados en materia financiera, económica, normativa" (p. 5). Esto significa, sin lugar a duda, que las juntas deben tener la autonomía necesaria para la contratación de estos profesionales; también la libertad para escoger o seleccionar, sin intervención de terceros, a su representante legal. Puesto que los comités de supervisión no cuentan con personería jurídica propia para proceder con la contratación de los profesionales que necesita, el representante designado de la cooperativa es quien firma los contratos de estos profesionales, en representación de los miembros de los comités de supervisión.

Para cumplir con las responsabilidades que la ley les impone a los miembros del CSA se les tiene que reconocer su autonomía ${ }^{3}$ e independencia. Por lo tanto, es indispensable evitar que la junta de directores, el consejo de administración, y mucho menos el principal ejecutivo, decida ex parte cuándo, cómo y a quién contratar, o en qué momento dejar sin efecto una contratación vigente; estos hechos violan la Carta

2 Este evento fue auspiciado por la Alianza Cooperativa Internacional (ACl), y se llevó a cabo en San José, Costa Rica en 2008. La ponencia de la investigadora se tituló "Foro de Comité de Vigilancia. ¿Qué debe hacer y qué no deben hacer los Comités de Vigilancia?".

3 Según el Diccionario de la Real Academia Española (2018), la palabra "autonomía" significa: "1. f. Potestad que dentro de un Estado tienen municipios, provincias, regiones $\mathrm{u}$ otras entidades, para regirse mediante normas y órganos de gobierno propios. 2. f. Condición de quien, para ciertas cosas, no depende de nadie". 
Circular 01-03 de la COSSEC, supra, evitando que los integrantes del CSA puedan descargar responsablemente sus deberes y responsabilidades.

En reconocimiento de las múltiples tareas y responsabilidades que la ley le impone a los miembros del CSA -y de las competencias específicas que surgen del Artículo 5.13 de la Ley 255-2002 y del Artículo 16.0 de la Ley 239-2004, según enmendadas - se les tiene que caracterizar por ser órganos soberanos dentro de su competencia legal e independiente, sin estar sometidos a las determinaciones arbitrarias de otros componentes de la cooperativa, a quienes tienen el deber de supervisar y fiscalizar. En consecuencia "no es el que las leyes le exigen, sino más bien, es el de valerse de terceros especializados en materia financiera, económica, normativa [...]" (Duran, 2004, p. 3), necesarios para poder descargar sus responsabilidades ministeriales.

Según el Proyecto de Ley Marco, supra, redactado por la Organización de las Cooperativas de América (OCA), los miembros de los comités de supervisión tienen a su cargo fiscalizar la actividad económica y social de la cooperativa, y velar para que la junta de directores o consejo de administración cumpla con la ley, el estatuto, los reglamentos y las resoluciones emitidas por la asamblea (Artículo 75). Es importante destacar que los comités de supervisión pasan juicio, fiscalizan y supervisan hechos ya consumados (o acciones realizadas) por los distintos miembros de los cuerpos directivos u órganos, incluyendo la administración o el ejecutivo. En consecuencia, los exámenes que realizan aplican a eventos pasados que -para ser investigados, analizados y considerados - demandan destrezas, preparación, experiencia, asesoramiento y representación profesional adecuada y oportuna. El papel que desempeñan los cuerpos de supervisión o vigilancia son vitales para el normal funcionamiento de las cooperativas. Por ejemplo, debido a que las personas que componen estos cuerpos de vigilancia son electos o nombrados directamente por la asamblea, conforman el único cuerpo de dirección dentro de la organización cooperativa; incluso deben realizar una supervisión sistemática del funcionamiento de la cooperativa en general y señalar las deficiencias, irregularidades o ilegalidades cometidas por los demás cuerpos directivos, incluidos los miembros de la junta de directores o el consejo de administración y el principal ejecutivo.

La Ley 255, supra, dispone que será la junta de directores o consejo de administración quien asignará a los comités de la cooperativa los recursos razonables para realizar sus funciones, siendo "condición previa a la asignación de dichos recursos que los comités preparen un plan de trabajo específico y concreto, cónsono con la

4 Esta se conoce también con el nombre de Ley General de Sociedades Cooperativas de Puerto Rico. 
política administrativa y operacional de la cooperativa que cuente con la aprobación expresa de la Junta" (Artículo 5.10, b, 11). Una vez aprobada la solicitud de presupuesto, que incluye partidas para la contratación de servicios profesionales, los miembros de los comités de supervisión pueden y están facultados para seleccionar a su representante legal o profesional sin intervención de terceros extraños. Lo contrario provocaría una violación crasa a la autonomía de estos cuerpos directivos de supervisión y fiscalización, evitando que las investigaciones que se realicen puedan concluir o se vean afectadas, o que los resultados no puedan ser elevadas a los organismos ni autoridades competentes.

Bajo nuestro estado de derecho cualquier persona, incluyendo a los miembros de los comités de supervisión, tienen derecho a seleccionar su propia representación legal y que esta sea adecuada y efectiva (Lizarribar y Martínez, 1988). En ese orden de ideas, las preguntas que debemos formularnos son: ¿En qué forma puede ser adecuada y efectiva una representación legal impuesta por los miembros de la junta de directores, el consejo de administración, el principal ejecutivo o su asesor legal, cuando la lealtad del abogado tiene que ser con aquellos que decidieron contratarlo en el ejercicio de su autonomía? ¿Cómo puede existir lealtad y confianza con un abogado impuesto por los miembros de la junta de directores, el consejo de administración, su asesor legal o la administración, mediante un tecnicismo jurídico para impedir que el asesor legal de la otra parte pueda descargar sus responsabilidades profesionales? ¿Qué garantías de estabilidad legal tendrían los miembros de los comités de supervisión, si están sujetos a la discreción inadecuada de los miembros de la junta de directores (o consejo de administración), su asesor legal (o administración) para evitar que las investigaciones realizadas sigan su curso o no puedan elevarse a las autoridades competentes?

El derecho de los miembros del CSA a tener una efectiva y adecuada representación legal queda menoscabado cuando el principal ejecutivo de una cooperativa (que está en un nivel inferior en la jerarquía de la estructura organizacional) y los miembros de la junta de directores o consejo de administración pretenden descalificar a un abogado que le presta servicios al comités de supervisión e imponer su criterio de selección, probablemente con otro de su predilección, desleal e incompetente para la tarea que se le asigna. La determinación unilateral para descalificar a un abogado, así como la presentación de quejas éticas en su contra, como mecanismo de represalia o para acallar su voz, son un asunto muy serio, pues involucra derechos y afecta la capacidad para descargar las funciones, responsabilidades, deberes y obligaciones de los miembros de los comités de supervisión y del propio abogado, quienes tienen derecho a representaciones 
adecuadas y competentes, lo que incluye el derecho a seleccionar su representación legal con base en su predilección.

En la Carta Normativa 01-03, supra, ${ }^{5}$ emitida por COSSEC, y que no ha sufrido modificaciones o enmiendas, se indica que "es importante e imprescindible para el sano funcionamiento de las Cooperativas", así como para el fortalecimiento interno de las mismas, que cada organismo cumpla a cabalidad con sus propias funciones y que el Comité de Supervisión tenga la responsabilidad de fiscalizar y la Junta de Directores la responsabilidad de administrar y que no cumplir con esas funciones implicaría una violación a los deberes ministeriales. En esta carta se establecieron instrucciones para atender las relaciones entre los miembros de la junta de directores y los comités de supervisión, siendo su génesis el producto de las varias consultas recibidas en COSSEC para solicitar que se aclaren las funciones, deberes y responsabilidades de estos cuerpos directivos en las cooperativas.

En respuesta, la agencia de gobierno concluye que las leyes vigentes le imponen al comité de supervisión la función primordial de vigilancia de la cooperativa, en cuyo caso tiene el deber de fiscalizar su actividad económica y social. Así mismo, el comité de supervisión tiene la obligación de velar porque la junta de directores cumpla con las disposiciones de ley, los reglamentos y las resoluciones de las asambleas, sin entorpecer las funciones y actividades de los demás organismos internos que conforman la cooperativa.

Una vez que la asamblea de la cooperativa ha aprobado el presupuesto, se concede un mandato para proceder conforme a derecho, lo que incluye la asignación de los recursos necesarios a los comités de supervisión para que estos puedan descargar sus responsabilidades.

En la Carta Normativa 01-03 se indica que, de conformidad con los principios cooperativistas de independencia, autonomía y control democrático, la Asamblea Legislativa de Puerto Rico, mediante la Ley 114 de 2001, delegó a la propia cooperativa la responsabilidad de manejar sus asuntos internos y de resolver los conflictos internos que se generen. Según la estructura operacional de la cooperativa, este control está dividido en diferentes organismos para crear un sistema de poderes segregados, en el cual el comité de supervisión funge como el organismo fiscalizador y la junta de directores como el organismo administrador. A tono con lo anterior, la carta señala que es imprescindible para el sano funcionamiento de las cooperativas, y para su fortalecimiento interno, que cada organismo cumpla a cabalidad con sus propias funciones, en otras palabras, que el comité de supervisión fiscalice y la junta de directores administre. El incumplimiento de estas funciones implicaría una violación 
a los deberes establecidos en las leyes aplicables, por lo que es necesario que los organismos directivos de las cooperativas viabilicen con diligencia los recursos, la información y demás requerimientos del CSA, para que este último pueda cumplir con sus funciones.

Los comités de supervisión tienen autonomía para seleccionar a su asesor legal o perito profesional, cuyos gastos se giran contra el presupuesto debidamente aprobado por la junta de directores y es avalado por la asamblea. Esta afirmación encuentra apoyo en una facultad análoga que encontramos en el Artículo 5.10 (b)(14), que le impone a la junta de directores de toda cooperativa la obligación de llevar a cabo la contratación de contadores públicos autorizados. De igual forma, los comités de supervisión están investidos de la facultad y el deber de cumplir con las obligaciones que le impone el Artículo 5.13 de la Ley 255, supra, entre las que se encuentra: a) realizar intervenciones que considere necesarias y oportunas, b) vigilar la legalidad de los actos de la junta y la gerencia; para lo cual es necesario contar con profesionales de su entera confianza. Esto solo se puede llevar a cabo a través del principal ejecutivo, sin que ello signifique que el cliente del asesor legal es la cooperativa, ya que llegar a esa conclusión desvirtúa los propósitos para los cuales fue contratado. Una vez que se aprueba el presupuesto de los comités de supervisión para cumplir con sus deberes ministeriales y funciones, debe cesar la intervención por parte de la junta y del principal ejecutivo con dicho comité, respecto a las funciones que ejercerá este con las cantidades asignadas y con las encomiendas que les puedan ofrecer los profesionales contratados para cumplir con el descargo cabal de sus responsabilidades ministeriales.

\section{Análisis de los cánones de ética profesional $^{6}$}

Al analizar y aplicar los Cánones de Ética Profesional a una situación como la que hemos expuesto, y para lograr instituir y mantener un orden jurídico íntegro y eficaz, que goce de la completa confianza y apoyo de la ciudadanía y en particular de la matrícula de socios que existe en una cooperativa, se les impone a los miembros de la profesión jurídica el deber de desempeñar su alto ministerio con la mayor y más excelsa competencia, responsabilidad e integridad. Puesto que una de las principales funciones de los juristas es el servicio a la sociedad, este servicio tiene que estar dirigido, principalmente, a lograr la existencia real de un orden jurídico íntegro y eficaz,

6 Ver: http://www.lexjuris.com/abogado/lexcodigoetica.htm 
orientado esencialmente por los principios de vida democrática y respeto a la inviolable dignidad del ser humano que rigen la convivencia social en el país. En ese sentido, se reconoce la existencia de un interés social en que todo ciudadano que lo necesite tenga fácil acceso a los servicios legales de abogados cuya conducta sea siempre honrosa, diligente y educada, con un compromiso solemne e inquebrantable, no sólo de conducir su propia persona de acuerdo con los principios éticos, sino también de velar porque la conducta de sus compañeros de profesión se rija igualmente por estas exigencias.

A partir de estas obligaciones de carácter ético profesional, surge la responsabilidad del asesor legal de los miembros del comité de supervisión de ayudar a que estos instituyan y mantengan, con su ayuda, un orden jurídico íntegro y eficaz, que goce de la completa confianza y apoyo de los miles de socios dueños que componen la cooperativa. La función de este asesor, como jurista, debe ser la de asesorar y representar única y exclusivamente a los miembros de los comités de supervisión, promoviendo con su intervención el acceso de los miembros de los comités de supervisión a servicios de asesoramiento legal. Estas funciones deben cumplirse mediante una conducta honrosa, diligente y educada, que permita al asesor legal garantizar que los miembros de estos cuerpos directivos - a quienes no se les reconoce la importancia que merecen - tengan acceso a una representación capacitada, íntegra y diligente. Estas normas, junto con los postulados que encierran, constituyen principios y valores que cualquier asesor legal o jurista que preste servicios legales a los miembros de un comité de supervisión debe observar, luchando por los más necesitados, ayudándoles a prevalecer en sus justos reclamos y en el cumplimiento y descargo de sus deberes ministeriales.

En el caso de Puerto Rico, el Canon 2 de los de Ética Profesional, supra, aplicable a la profesión legal, establece la obligación del jurista cuando acepta una representación legal, en los siguientes términos:

Canon 2.

Responsabilidad del abogado de laborar por que toda persona tenga representación legal adecuada: Calidad de los servicios legales

A fin de viabilizar el objetivo de representación legal adecuada para toda persona, el abogado también debe realizar esfuerzos para lograr y mantener un alto grado de excelencia y competencia en su profesión a través del estudio y la participación en programas educativos de mejoramiento profesional: ayudando a los tribunales, juntas y demás autoridades en la 
promulgación de normas y requisitos adecuados que orienten los programas educativos de las escuelas de derecho y el proceso de admisión al ejercicio de la profesión; y sirviendo en comités, seminarios y organismos con funciones relacionadas con la divulgación, mejoramiento y aplicación de los cánones de responsabilidad profesional.

Según Mariano Negrón (1993), "en la práctica del comercio es aceptable que la mercancía se exhiba en vitrinas y escaparates. En la práctica de la abogacía la mercancía de que se dispone es el talento, el conocimiento del Derecho y las destrezas del abogado, mercancía que se anuncia por si sola a través de la reputación bien ganada [...]". (p. 21).

La relación profesional que surge cuando el consejero legal es contratado por la cooperativa para asesorar a los miembros de los comités de supervisión debe fundamentarse en la absoluta confianza, a partir de un trato profesional caracterizado por la mayor capacidad, la más devota lealtad y honradez, poniendo todo su empeño en llevar a cabo en esa forma su gestión profesional, sin temor a devolver favores o por miedo a perder la estimación popular. No obstante, es preciso destacar que el Derecho Cooperativo es una de las áreas del derecho que normalmente no se estudia ni se enseña en las escuelas de leyes, por lo que esta debe ser una de las áreas que necesita mayor desarrollo. En consecuencia, es impropio de un abogado asumir una representación profesional cuando debe estar consciente que no puede rendir una labor idónea competente, y que es su deber defender los intereses de sus clientes diligentemente, desplegando en cada caso su más profundo saber y habilidad; actuando en la forma en que la profesión jurídica, en general, estima adecuada y responsable; no debe ceder en el cumplimiento de su deber por temor a perder estima dentro de los otros componentes de la cooperativa, incluyendo aquellos que controlan y administran el presupuesto de la organización y la contratación de servicios, y mucho menos a perder la estimación de terceros extraños a la organización. Su conciencia tiene que estar bien asentada en los principios y valores cooperativos.

\section{Análisis de la Norma Ética en el Derecho Corporativo Vs. Derecho Cooperativo}

Como ya previamente expresamos, en Puerto Rico, como seguramente ocurre en otros países hermanos, existe una norma ética aplicable a la clase togada que dispone que el abogado en una corporación regular le debe lealtad a la persona jurídica 
sobre los oficiales, directores y accionistas. La norma jurisprudencial señala que, en ese tipo de corporación, cuando el abogado la representa, el cliente es la corporación y no es el presidente ni es el secretario, ni es tal o cual accionista. No obstante, es preciso destacar que en las corporaciones regulares no existen los comités de supervisión mandatados por ley, por lo que no podemos detenernos en el tiempo sin advertir que las cooperativas, que son corporaciones sin fines de lucro con una finalidad muy distinta a las corporaciones regulares, son corporaciones únicas en su clase (sui generis). Bajo esta prohibición ética, el cliente del abogado es la corporación y no sus directivos, oficiales o accionistas; sin embargo, en el caso de las cooperativas, los clientes del asesor legal serían los miembros del comité de supervisión de la cooperativa, a quienes se obliga a asesorar y representar y de quienes, en la entrevista inicial o por las comunicaciones sostenidas antes de su contratación, pudo o puede obtener secretos y confidencias de este cuerpo directivo que justifican su contratación.

El Derecho Cooperativo, como cualquier otro cuerpo de normas jurídico-legales, no puede ser estático o rígido y pretender que las normas éticas aplicables a las corporaciones regulares sean aplicadas en forma autómata, sin considerar la intención que tuvo la Asamblea Legislativa al aprobar las leyes que rigen al cooperativismo y donde por mandato de ley se crea un cuerpo directivo con funciones específicas de fiscalización, vigilancia y de supervisión que solamente le responden al soberano, es decir, a la Asamblea de Socios, según surge del organigrama o estructura organizativa clásica de cualquier cooperativa.

De modo que el conflicto entre los distintos componentes de la cooperativa y los miembros de los comités de supervisión surge naturalmente porque la propia ley los obliga a investigar, auditar, fiscalizar y realizar todas aquellas intervenciones que considere necesarias y convenientes para salvaguardar los intereses de la cooperativa. El propósito de la norma ética (antes citada), lo que intenta evitar, es el conflicto de intereses cuando el abogado ha adquirido confidencias de ambos clientes, o sea, de los miembros del CSA y de los representantes de la cooperativa o su junta de directores.

Las organizaciones cooperativas se rigen por unos principios y valores que solamente existen en la filosofía cooperativa y que por su importancia destaco, a saber: ayuda mutua, responsabilidad, democracia participativa, igualdad, equidad y solidaridad. Adicionalmente, sus miembros creen en los valores éticos de la honestidad, transparencia, responsabilidad social y preocupación por los demás.

Así que cuando el asesor legal decide aceptar la representación de los miembros de los comités de supervisión debe estar consciente de los deberes que la ley 
les impone a sus clientes, incluyendo vigilar la legalidad de los actos de la junta de directores y de la gerencia, que forman parte de la Cooperativa; por lo que su juicio nunca deberá verse comprometido o afectado por sus expectativas o intereses personales o atender situaciones o asuntos que pudieran afectar cualquier interés de un cliente anterior. Para evitar el conflicto de intereses, ni la cooperativa ni el principal ejecutivo o sus gerenciales deben haber tenido ninguna relación profesional previa con el abogado.

Uno de los conflictos puede surgir cuando un abogado o abogada asume la representación legal de un cliente, a sabiendas de que su juicio profesional puede verse afectado por sus intereses personales (Menéndez, 2011). Las relaciones entre abogado y cliente están basadas fundamentalmente en una mutua confianza, más aún cuando se le impone al abogado la obligación de guardar a su cliente la más estricta fidelidad, prohibiéndole divulgar secretos y las confidencias que aquel le ha hecho. Esa lealtad es indivisible y continua después de cesar como abogado (Guzmán, 1958). Se trata, pues, de una relación privilegiada entre el asesor legal y los miembros de los comités de supervisión.

En el descargo de sus responsabilidades profesionales, el asesor legal debe estar consciente y cuidarse de que sus actuaciones no den margen a la más leve sospecha de que defiende intereses encontrados. Para esto, el contrato de servicios profesionales se debe establecer en forma diáfana y prístina, señalando que solo asesorará y representará a los miembros del comité de supervisión en el descargo de sus responsabilidades impuestas por las leyes vigentes (Roldán y Medina, 1982).

Es necesario conocer la filosofía, los valores y la naturaleza jurídica única del cooperativismo para poder entender, en su justa perspectiva, la manera y forma de actuar de los asesores legales de los miembros de los comités de supervisión; y no a partir del Derecho de Corporaciones o Mercantil que, según lo exigen algunas leyes vigentes, a esa relación contractual entre la cooperativa y el asesor legal de los CSA, le es aplicable la figura del "acto cooperativo", por lo que cualquier controversia que surja se tiene que resolver mediante el Derecho Cooperativo que, en el caso de Puerto Rico, la ley aplicable dispone:

\author{
Artículo 2.3.-Actos Cooperativos \\ Son actos cooperativos los realizados entre las cooperativas y sus socios, o \\ por las cooperativas entre sí, con el Estado Libre Asociado de Puerto Rico, \\ en cumplimiento con su objetivo social, regidas por el Derecho Coopera- \\ tivo. (Ley Núm. 239 de 1 de septiembre de 2004).
}


Por mandato de ley, las controversias y los actos al interior de la cooperativa -que surgen como consecuencia de las funciones, obligaciones y deberes que las leyes vigentes les imponen a los miembros del comité de supervisión, incluyendo la contratación profesional necesaria para que puedan descargar sus funciones ministeriales-, tienen que ser resueltos y atendidos mediante la aplicación del "acto cooperativo", que constituye una acción cobijada bajo el palio de esa figura jurídica. Quien no lo comprenda ni aplique, no conoce ni domina el Derecho Cooperativo, por lo tanto, estaría negando la autonomía que internacionalmente los tratadistas y doctrinarios le reconocen a esta rama del Derecho.

En Cooperativa de Vivienda Rolling Hills v. Doris M. Colón Lebrón, el Tribunal Supremo de Puerto Rico expresa que "[...] la Ley General de Sociedades Cooperativas, supra, tiene como objetivo dotar a las cooperativas y al sector cooperativo, en general, de un marco jurídico para su organización, funcionamiento y regulación. 5 L.P.R.A. 4381 (Propósito)". A nuestro juicio, tal afirmación de política pública, ratificada en ese caso, sería suficiente para concluir que las cooperativas en Puerto Rico se rigen por leyes especiales que crean una forma de gobernanza única que es muy distinta a las corporaciones regulares. En consecuencia, se tiene que reconocer que en las cooperativas existen, por disposición de ley, los comités de supervisión que, para poder descargar su responsabilidad fiduciaria, deben contar con las herramientas necesarias, lo que incluye el asesoramiento legal. En este caso, el Tribunal Supremo afirma que las leyes especiales aplicables a las cooperativas "reglamentan a las cooperativas y [a] las personas que en ellas participan" y añade que "las cooperativas organizadas de conformidad con este capítulo se regirán por sus disposiciones y, en general, por el derecho cooperativo".

En tales casos, cuando se contrata a un perito del derecho para que funja como asesor legal de los miembros de un comité de supervisión, la cooperativa tiene que estar representada por su principal ejecutivo con el único fin de suscribir un contrato de servicios profesionales representando a los miembros del comité de supervisión, siendo este un "acto cooperativo".

El tratadista Dante Cracogna, reconocido por sus estudios en Derecho Cooperativo, nos ilustra sobre este tema, cuando afirma: "Cuestión importante que las organizaciones de crédito cooperativo han de destacar ante propios y ajenos es lo concerniente al sentido ético que informa su actividad y que les imprime un sello peculiar que las diferencias de otras organizaciones que atienden la misma actividad" (2019, comunicación verbal).

También señala que "en razón de las apuntadas diferencias corresponde también distinguir cómo se organiza y funciona adecuadamente el gobierno de las 
cooperativas sin trasladar recetas de otras formas de organización empresarial ajenas a su naturaleza" (Cracogna, 2019, p. 155). Para el investigador, las corporaciones regulares son empresas por entero diferentes de las cooperativas, pues estas no se constituyen en consideración al capital sino a las personas y realizan una actividad orientada a prestar servicios y no a obtener ganancia. Afirma que

Por si fuera poca la diferencia, en las cooperativas los asociados gobiernan conforme con al principio de igualdad democrática y no según el capital aportado. De allí que identificar "gobierno corporativo" con "gobierno cooperativo" resulte, cuando menos, inapropiado; una cosa es el gobierno de las corporaciones y otra distinta el gobierno de las cooperativas, pues uno y otro persiguen objetivos claramente diferentes. (p. 157).

Nos continúa ilustrando al indicar que "el (buen) gobierno de las cooperativas consiste en adoptar la organización y el funcionamiento que aseguren la consistencia con su valores y principios; no en copiar las reglas o pautas del gobierno corporativo, aunque en ciertos aspectos puedan coincidir" (p. 5). Con respecto al papel de los comités de supervisión o juntas de vigilancia en las cooperativas, señala:

Por otra parte, de acuerdo con el sistema de organización interna que es común en las cooperativas en América Latina, a la asamblea también incumbe la elección de un órgano de control específicamente encargado de supervisar el cumplimiento de la ley y del estatuto por parte del órgano de administración. De esta manera se cierra el círculo según el cual la asamblea designa a los administradores y a la vez elige a quienes habrán de controlar la actividad de éstos, siempre sobre una base democrática y en ambos casos con sujeción a las directivas de aquélla. Por lo tanto, es difícil exagerar la transcendencia de la asamblea dentro del sistema de gobierno cooperativo.

El órgano de supervisión o fiscalización interna es distinto e independiente del órgano de administración, por lo cual, las funciones de uno y otro se hallan claramente diferenciadas, sin que ello obste a que los administradores puedan organizar alguna forma de control interno; pero la función específica de control recae en un órgano diferenciado que rinde cuentas a la asamblea.

Parece claro que algunos aspectos del gobierno corporativo son también aplicables a las cooperativas toda vez que la gestión transparente 
y la información confiable constituyen objetivos comunes, al igual que la realización de una gestión idónea dotada de capacidad técnica. Sin embargo, ha de tenerse presente que éstos son aspectos instrumentales que se hallan orientados a objetivos diferentes en uno y otro caso. (p. 7).

Concluye Cracogna que "[...] el esquema de organización interna de las cooperativas suele estar conformado por tres órganos, a saber: asamblea, consejo de administración y junta de vigilancia, que tienen asignada cada uno de ellos una función específica y diferenciada: gobierno, administración y control, respectivamente. La correcta aplicación de dicha estructura y el apropiado desempeño de tales órganos habrán de conducir a un adecuado gobierno cooperativo" (p. 6).

Otro comentarista y estudioso del Derecho Cooperativo, Félix Cristiá Martínez (2019), nos indica que el cooperativismo, hasta ahora, ha tenido que operar con normas y reglas que no coinciden con su filosofía diferenciada.

En mayo de 2020, el Organismo Regulador de las Cooperativas en Puerto Rico dictó una Resolución Administrativa en el caso Q-19-98-014, resolviendo una querella presentada por el Sr. Robert Quintero Negrón contra la Cooperativa de Ahorro y Crédito Zeno Gandía, su presidente ejecutivo y los miembros de la junta de directores. El ente concluyó que la administración y dirección de las cooperativas de ahorro y crédito se facultan y recaen a través de los cuerpos directivos, esto es, la junta de directores, el comité de crédito, el comité de supervisión y el comité de educación, entre otros. (Art. 1.03 [m] de la Ley Núm. 255).

Cristiá concluye, además, que el comité de supervisión tiene facultades para seleccionar a su asesor legal y que la determinación que recaiga sobre este particular incide en el alcance de las facultades y el nivel de autonomía y autoridad de este comité; igualmente, dicha acción está permitida en la Ley Núm. 255, supra, siempre y cuando someta una solicitud de asignación de fondos y un plan de trabajo. La junta de directores tiene la responsabilidad de asignar a los comités de la cooperativa los recursos razonables para realizar sus funciones; en tanto que el comité de supervisión tiene la responsabilidad de solicitar a la junta que contrate el personal que necesite el comité para llevar a cabo sus funciones, quedando sujeto ese ejercicio a la asignación de fondos que autorice la junta, de acuerdo con el plan de trabajo presentado por el comité, siendo la presentación de un plan de trabajo un requisito sine qua non previo a la asignación de fondos.

A esos fines, la ley le impuso la responsabilidad de realizar las intervenciones que considere necesarias y vigilar la legalidad de los actos de la junta y la gerencia. Es razonable pensar, entonces, que para cumplir la función ministerial de vigilar la 
legalidad de los actos de la junta y la gerencia se requiere contar con el consejo y la asistencia de un abogado, a través de una relación basada en la confianza y la lealtad con su representado, entiéndase en este caso, el comité de supervisión, lo que implica que el comité puede seleccionar al asesor que los asistirá siendo su prerrogativa seleccionar sus recursos. Cristiá añade que, si bien la junta tiene la facultad de definir los parámetros de contratación de recursos profesionales, la selección del recurso solicitado no puede ser uno de estos, ya que el comité de supervisión es un cuerpo autónomo que goza de total independencia de criterio en el descargo de su función fiscalizadora y esto obedece a una medida de control con la finalidad de asegurar una fiscalización efectiva de la administración operacional y fiscal por parte del comité. Interpretar que la selección del abogado que asesorara al comité en sus funciones recae sobre la junta de directores, atenta contra la autonomía e independencia, particularmente si se considera que el consejo del abogado ayudará a que el comité cumpla su responsabilidad de vigilar la legalidad de los actos de la junta y la gerencia, entre otras?

En su resolución administrativa, expresa que parecería no tener sentido que la junta escoja el abogado de su confianza para que asesore al comité que por ley tiene la responsabilidad de supervisar y vigilar la legalidad de sus actos. ¿Cómo podría ser adecuada y efectiva una representación impuesta en tales circunstancias?

Son diferentes - aunque estén relacionadas - la autoridad para contratar servicios profesionales, asignar fondos para estos servicios y seleccionar el recurso profesional que los brindará. Por ejemplo, la facultad para llevar a cabo cada una de estas acciones no recae sobre una misma persona u organismo. Además, después de analizar la legislación vigente y considerar las facultades de la junta de directores, no se puede interpretar que esta última tenga la facultad de seleccionar los recursos requeridos por los comités, siendo la única condición o sujeción para la asignación de los recursos preparar un plan de trabajo que sustente la solicitud de los recursos y el desembolso de fondos. El comité de supervisión tiene facultades y responsabilidades fiscalizadoras particulares e inherentes que lo envisten de autonomía e independencia; esta autonomía exige que la selección del recurso legal que aconsejará y asistirá al comité de supervisión en sus funciones recaiga sobre dicho comité y no sobre la junta de directores. Concluir lo contrario, iría en detrimento de la autonomía y naturaleza del comité de supervisión e implicaría otorgar un poder supremo, que no tiene, a la junta de directores que alteraría el balance de poderes entre los cuerpos directivos.

El derecho de los miembros del CSA a tener una efectiva y adecuada representación legal queda menoscabado cuando el principal ejecutivo de una

7 Ver: Parte V, segundo párrafo, página 11 de la Resolución Administrativa de COSSEC. 
cooperativa (que está en un nivel inferior en la jerarquía de la estructura organizacional), junto con los miembros de la junta de directores, pretenden descalificar a un abogado que le presta servicios a los comités de supervisión e imponer su criterio de selección, probablemente con otro de su predilección. La determinación unilateral de la descalificación de un abogado, así como la presentación de quejas éticas en su contra como mecanismo de represalia o para acallar su voz, es un asunto que afecta derechos y obligaciones, incluyendo la capacidad para descargar en forma responsable, profesional y adecuada las funciones, responsabilidades, deberes y obligaciones de los miembros de los comités de supervisión y del propio asesor. De otra parte, los profesionales del derecho están legitimados a ejercer su profesión, representando a aquellos clientes que decidan, en forma libre y voluntaria, contratarlos.

Los comités de supervisión son cuerpos fiscalizadores que tienen unas facultades conferidas por ley, precisamente para que puedan llevar a cabo sus funciones con independencia de criterios, sin estar sujetos a las decisiones caprichosas y arbitrarias de algunos miembros de las juntas de directores, principales ejecutivos y asesores legales. El hecho de que la junta y el principal ejecutivo hayan contratado a sus asesores legales, en cuya decisión no intervienen los comités de supervisión, no puede constituir un impedimento para que sus miembros soliciten contratar igualmente a los recursos profesionales necesarios para llevar a cabo sus funciones, para asesorarlos y que los representen cuando decidan descargar su responsabilidad legal de realizar aquellas intervenciones que consideren necesarias y convenientes para el mejor descargo de los deberes que le impone la ley.

\section{Referencias}

Corporación para la Supervisión y Seguro de Cooperativas en Puerto Rico. (26 marzo de 2006). Carta Circular 01-03. https://n9.cl/nxoa

Corte Suprema de Puerto Rico. (1958). In re Antonio Guzmán Juarbe, 80 D.P.R. 713.

Corte Suprema de Puerto Rico. (1982). In re Roldán y Medina, 113 D.P.R. 238.

Corte Suprema de Puerto Rico. (2011). In re Gordon Menéndez, 2011 TSPR 196.

CARTA CIRCULAR 03-02 file://C:/Users/Lina/Downloads/CC03-02.pdf 
Obligaciones éticas y deberes fiduciarios del representante legal de los miembros del comité de supervisión de una cooperativa

Cristiá-Martínez, F. (2019). Principios elementales del Derecho Cooperativo. Confederación de Cooperativas del Caribe y Centro América.

Dante, C. (2019). Gobierno corporativo v. Gobierno cooperativo. Congreso Continental de Derecho Cooperativo. Cooperativa de las Américas.

Durán-Vargas, Á. (2004). El rol de la Junta de Vigilancia en el Sistema de Control Interno de las Cooperativas deAhorroy Crédito de América Latinayel Caribe. (Primera edición). Confederación Alemana de Cooperativas. www.dgrv.org

Ley de la Corporación Pública para la Supervisión y Seguro de Cooperativas de Puerto Rico. Ley Núm. 114 de 17 de agosto de 2001. https://n9.cl/ohb51

Ley General de Sociedades Cooperativas de Ahorro y Crédito de Puerto Rico. Ley Núm. 255 de 28 de octubre de 2002, según enmendada. https://n9.cl/dtvo

Ley General de Sociedades Cooperativas de Puerto Rico. Ley 239 de 28 de octubre de 2004, según enmendadas. https://n9.cl/dtvo

Ley Marco para las Cooperativas de América. (2009). XV Conferencia Regional la ACl-Américas. Alianza Cooperativa Internacional para las Américas. https://www.aciamericas.coop/IMG/ pdf/LeyMarcoAL.pdf

Muñoz, X. (2006). Principios para un buen gobierno corporativo. Revista COLAC. http://www.colac. com/revista/junio/gobierno-corporativo.html

Negrón-Portillo, M. (1993). Ética profesional. https://www.amazon.com/-/es/Luis-Mariano-NegronPortillo/dp/1596080663/ref=sr_1_7?dchild=1\&qid=1620333417\&refinements=p_27\%3AMariano+Negro\%CC\%81n-Portillo\&s=books\&sr=1-7

Ríos-Barboza, M. (2008). Responsabilidad social cooperativa y vida democrática. XVI Conferencia Regional de la Alianza Cooperativa Internacional (ACI), San José, Costa Rica. https://www. javeriana.edu.co/Facultades/fear/ier/?idcategoria=1107

Tribunal Supremo de Puerto Rico. (1970). Cánones de ética profesional. https://n9.cl/r2mi

Tribunal Supremo de Puerto Rico. (15 de enero de 2020). Cooperativa de Vivienda Rolling Hills v. Doris M. Colón Lebrón, 2020 TSPR 004.

Tribunal Supremo de Justicia. Sentencia del 30 de junio de 1988. Lizarribar v. Martínez Gelpí, 121 DPR 770. 